\title{
«RESCALING THE EUROPEAN STATE. THE MAKING OF TERRITORY AND THE RISE OF THE MESO»
}

\author{
de Michael Keating (2013). \\ Oxford University Press \\ por José Ignacio Vigil \\ Universidad Nacional del Litoral
}

Para algunos, Michael Keating (profesor de la Universidad de Aberdeen, Escocia) puede ser conocido por sus aportes a las discusiones regionalistas e incluso urbanistas (ver por ejemplo Keating, 1998, 2003, 2004), aunque a discutido mayormente aspectos vinculados a la política europea, el nacionalismo e incluso sobre aspectos vinculados a la metodología en las ciencias sociales. Este libro es de hecho el resultado de un ambicioso proyecto dirigido por Keating sobre las implicancias del reescalamiento en Europa, con estudios de casos vinculados a los procesos de reorganización fruto de ese reescalamiento por parte de grupos de interés sociales y económicos en varios países europeos (Alemania, Austria, Bélgica, Francia, Italia, UK, España, etc.). A juicio de muchos analistas, el libro constituye una importante -y muy oportuna - aportación al debate conceptual y de la política territorial en Europa y/o de la denominada política de cohesión de la Unión Europea (ver Barca, 2009).

Keating parte de un diagnóstico conceptual más o menos conocido en sus aspectos generales sobre los cambios recientes en la dinámica económica global del capitalismo que repercutieron en las transformaciones del Estado nación y del Estado nacional —ver por ejemplo los análisis de Bob Jessop que reseñamos en números anteriores de DAA- 
námicas económicas del capitalismo y las transformaciones estatales han dado paso a su vez a la conformación de nuevas arenas para la política pública, modificando la estructura misma de la política, sus formas y sus límites, y generando novedosas y variadas dinámicas de acumulación y regulación (ej.: federalismos, gobiernos regionales, traspaso de competencias, autonomías regionales, etc.). Un emergente de estas transformaciones ha sido - en el análisis de Keating - el nivel "meso" de acción, no solo como nivel quizá más explícito de gobierno y regulación, sino también como espacio influyente de conformación de la vida social y de expresión política, como nueva arena de conformación de identidades, de culturas, de alianzas, de influencias, de conflictos, de expresiones contestatarias, de anidamiento de esquemas de poder, etc., etc., etc. Y aunque no es nueva la emergencia de estos nuevos espacios - dice Keating-, mientras los movimientos sociales y políticos tienden precisamente a politizarlos, y los actores económicos a buscar mayor movilidad, los Estados europeos por su parte han vuelto un tema recurrente de interés su preocupación por controlarlos. Cómo responden o han respondido los espacios regionales a estas transformaciones y contestaciones sea quizá el interrogante central sobre el que giran los aspectos conceptuales y empíricos de la propuesta de Keating.

El libro contiene discusiones sobre las teorías del territorio (y de las regiones), y sobre la posibilidad de repensar el territorio como una entidad topológica (con las consecuencias que eso tiene en términos de límites, de políticas, de identidades, de reacciones, etc.). Contiene debates sobre la idea misma del reescalamiento, sobre teorizaciones en relación con las posibilidades de los Estados de controlar los nuevos espacios regionales, y sobre ideas referentes a las potencialidades de los espacios regionales de avanzar en dirección opuesta a la centralización estatista. Quizá un capitulo interesante y hasta quizá interesante para el propio Keating en su escritura, sea el 7 , donde bucea sobre las posibilidades de la política y del gobierno al nivel "meso", una contante en sus preocupaciones académicas. El libro se sumerge también en la descripción y análisis de las respuestas desde los gobiernos meso regionales a las transformaciones estatales. Hacia el final, el libro Incluye también argumentaciones sobre las dinámicas recientes de centralización (o recentralización) y las de descentralización, en parte vinculadas algunos cimbronazos generados desde la crisis económico institucional europea del 2007. En ese camino, y como tema seguramente de próximas reseñas, Keating trabaja actualmente con ideas y proyectos vinculados a la temática de la independencia escocesa, y sobre aspectos relacionados con una mejora de la articulación entre académicos y policy makers en Escocia. Esperaremos sus nuevos resultados como inspiración y alimento del debate para pensar las políticas regionalistas latinoamericanas. 


\section{BIBLIOGRAFÍA}

Barca, F. (2009). An agenda for reformed cohesion policy. A place-based approach to meeting European Union challenges and expectations: prepared at the request of Danuta Hübner, Commissioner for Regional Policy.

Keating, M. (1998). The New Regionalism in Western Europe. Territorial Restructuring and Political Change Northampton: Edward Elgar Publishing Limited.

Keating, M. (2003). The Inventions of Region: Political Reestructuring and Territorial Government in Western Europe, pp. 256-277 in N. Brenner, B. Jessop, M. Jones \& G. MacLeod (eds.), State/Space. A Reader. Oxford, UK: Blackwell Publishing.

Keating, M. (ed.) (2004). Regions and Regionalism in Europe Cheltenham, UK: Edward Elgar.

Vigil, J.I. (2005). Reseña bibliográfica: El Futuro del Estado Capitalista (Cambridge University Press), de Bob Jessop. Documentos y Aportes en Administración Pública y Gestión Estatal, 4(5), 141-145.

\section{PARA CITAR ESTE ARTÍCULO:}

Vigil, J.I. (2015). "Reseña bibliográfica: Rescaling the European State. The Making of Territory and the Rise of the Meso, de Michael Keating", DAAPGE, año 15, №25, pp. 155-157. UNL, Santa Fe, Argentina. 
